\title{
ANTÍGONA: PALAVRA ORACULAR (PURA) E PALAVRA DO ANALISTA ${ }^{1}$
}

Heloisa Helena Marcon

Psicanalista (participante da Associação Psicanalítica de Porto Alegre/ Appoa), Mestre em Filosofia, UFRGS.
RESUMO: Tenta-se aproximar a palavra oracular ou pura do adivinho Tirésias na tragédia Antígona de Sófocles da palavra do analista numa psicanálise. Faz-se tal aproximação por meio da apresentação das características comuns as duas palavras em questão (do analista e do adivinho): potência de suspensão do sentido e abertura a outros sentidos - enunciação - presentes num enunciado ou discurso racional ou argumentativo.

Palavras-chave: Antígona, palavra pura, palavra do analista, suspensão e abertura de sentido.

ABSTRACT: Antigone: oracular word (pure) and word of the analyst. The present article makes the oracular or pure word of the soothsayer Tiresias in the Sophocles Antigone close to the word of the analyst in psychoanalysis. It makes such approximation through the presentation of the common characteristics of both words (the one of the analyst and the one of the soothsayer): power of suspension of the sense and opening to other senses - enunciation - present in a declaration or in a rational or argumentative discourse.

Keywords: Antigone, pure word, word of the analyst, sense suspension and opening.

\footnotetext{
${ }^{1}$ A inspiração deste trabalho advém, claramente, dos Seminários da Prof. ${ }^{a}$ Kathrin Rosenfield no PPG Filosofia/UFRGS, dos quais participei ao longo de meu mestrado. Mais especificamente, de comentários que se encontram no capítulo intitulado "Tirésias ou a palavra pura" de seu livro Antígona - de Sófocles a Hölderlin: por uma filosofia "trágica" da literatura, comentários com os quais, imediatamente, fui remetida à palavra do analista.
} 
$A$ ntígona de Sófocles é, como todas as tragédias, um texto emocionante, fascinante e, na mesma proporção - ou, justamente por tais características -, um texto complexo. Emocionante, fascinante ou inquietante e, assim, complexo, porque, como vemos na "Poética" de Aristóteles (1999), se trata de encenar os homens em ação - isso para sublinhar que não se trata de uma colocação em cena de caráteres, pois, para Aristóteles, os personagens adquirem caráter na realização de ações e não o contrário (personagens que agiriam para colocar em cena caráteres); assim o caráter é aquilo que revela determinada deliberação ou a escolha que se faz ou que se evita fazer. Para Aristóteles, então, importa deter-se no modo como as ações se dispõem, ou seja, na trama ou tecitura das ações.

Meu objetivo neste trabalho não é, no entanto, apresentar a tecitura das ações, mas, mesmo assim, será necessário apresentar minimamente tal trama para poder delimitar o estatuto da palavra de Tirésias, isto é, o estatuto da palavra oracular ou profética, ou ainda, palavra pura.

\section{A TRAMA DE ANTÍGONA}

Esta tragédia pressupõe o desenrolar dos acontecimentos da peça "Sete contra Tebas”, em que Ésquilo (1975) apresenta a batalha que os filhos de Édipo Polinices e Etéocles travaram um contra o outro na luta pelo trono de Tebas. Luta esta resultado do não-cumprimento por parte de Etéocles da decisão de Édipo da alternância de seus dois filhos no reinado de Tebas. Por isso, Polinices reúne um exército e tenta tomar o trono do irmão, mas, na batalha, eles matam um ao outro. É nesta situação que Creonte, como "herdeiro mais chegado do seu sangue”2 (SÓFOCLES, 1965, v.174) acaba por ocupar o trono e o poder de Tebas.

A peça se inicia com uma conversa entre Antígona e sua irmã Ismene sobre o edito recém proclamado por Creonte que determina o enterro de Etéocles e a proibição do enterro de Polinices, ambos igualmente irmãos de Antígona e Ismene. Antígona apresenta o edito à irmã, que ainda o desconhecia, e a convida para enterrar Polinices, apesar de saber da pena imposta ao transgressor do edito: lapidação em praça pública. O argumento de Antígona se baseia no respeito para com o laço de sangue - eles são irmãos - e à piedade para com os mortos - respeito para com as leis dos deuses subterrâneos ou inferiores. Ismene, no entanto, recusa o convite de Antígona. Mas esta, mesmo sozinha, está decidida a dar uma sepultura digna ao seu querido irmão.

Creonte apresenta-se para o Coro como novo rei devido a sua proximidade de sangue com os Labdácidas e fala de seu edito como uma primeira decisão

\footnotetext{
${ }^{2}$ No que se refere à utilização do texto de Sófocles, será utilizada a indicação dos versos em que aparecem na obra aqui utilizada como referência e não as páginas, para que seja possível ao leitor encontrar as passagens aqui apresentadas também em outras, inclusive, no grego.
} 
das normas que pretende pôr em prática para tornar grande a cidade de Tebas: "nunca em minha estima hão de ter direito igual os maus e os justos" (SÓFOCLES, 1965, v.207-208).

Um guarda chega ao palácio trazendo a notícia do enterro secreto do morto; ninguém viu quem o praticou. Na verdade, ele não foi propriamente enterrado, mas foi jogada sobre ele uma leve poeira. Como ninguém viu o autor de tal ato, o Coro entende o acontecimento como imposição dos deuses. Creonte não concorda com a idéia do Coro e ordena ao guarda que descubra o culpado e o traga até ele.

O guarda retorna trazendo, dessa vez, Antígona acorrentada. E conta a Creonte que, mais uma vez, Antígona praticava o ritual fúnebre e, perante o corpo de Polinices, lamentava-se e lançava maldições brutais contra os sacrílegos. Além disso, comenta o guarda, ela não nega que tenha cometido os crimes. Antígona apresenta como argumento do seu ato as não escritas e intangíveis leis dos deuses, as quais, por nada, transgrediria. Creonte entende que, mesmo sendo Antígona filha de sua irmã (Jocasta), ele não seria homem se não punisse tal ousadia, e ainda acusa Ismene de ser cúmplice do crime e, por isso, manda buscá-la.

Ismene afirma a Creonte ter parte igual no enterro do irmão e, portanto, a mesma culpa que Antígona, mas Antígona não aceita que a irmã tome para si um ato alheio. Creonte está decidido a matar suas duas sobrinhas, uma das quais - Antígona - noiva de seu filho Hémon.

Hémon e Creonte dialogam sobre a decisão de Creonte. Hémon tenta argumentar com seu pai a favor de Antígona falando do choro de toda a cidade pela sorte dela. Como Creonte mantém-se inflexível, Hémon afirma que se Antígona morrer, ela não morrerá sozinha, o que Creonte toma como uma ameaça a si e, portanto, fica enfurecido.

Por sugestão do Coro, Creonte decide poupar Ismene da morte. Sobre a morte de Antígona, ele dispõe o seguinte:

"Mandarei levá-la a um lugar deserto e enterrá-la viva em um antro rochoso, com comida, a fim de evitar sacrilégio e, para a cidade, a mácula de um crime. Lá talvez, rogando ao Hades, seu deus único, possa obter a graça de escapar à morte; ou aprenderá, pelo menos, que é esforço inútil honrar os deuses inferiores." (SÓFOCLES, 1965, v.774-780)

Creonte, por não condenar Antígona diretamente à morte, mas à vida subterrânea, sente-se livre da poluição que mais este sangue derramado causaria à cidade. Antígona, por ordem de Creonte, é levada pelos guardas para a prisão subterrânea. 
Eis que, por fim, entra Tirésias, o vidente cego, conduzido pelo menino que o guia. Creonte volta à cena para saber quais as novas trazidas por tal ancião. Interrogado por Creonte, Tirésias pede que o governante dê-lhe crédito e avisa: "Cuidado! Andas sobre um fio de navalha!” (SÓFOCLES, 1965, v.996). Em seguida, o velho descreve os sinais de sua arte para dizer a Creonte: "Vem do teu querer o mal desta cidade." (idem, v.1.015) e explica, relacionando tais sinais com o "cadáver desse filho de Édipo” (idem, v.1.018), afirmando que "Já os deuses recusam nossos sacrifícios e orações e a flama não sobe das coxas da vítima e as aves gritam maus augúrios fartas dessa graxa e desse sangue humano” (idem, v.1.019-1.022). O vidente cego pede, então, a Creonte: “Cede, pois à morte: poupa esse cadáver" (idem, v.1.029), perguntando-lhe: "Pode ser façanha assassinar um morto?” (idem, v.1.030). No entanto, Creonte responde negativamente, tomando as palavras do adivinho como ofensa a si (da mesma forma como, antes, tomou as palavras de seu próprio filho), reafirmando que “jamais sepultarei esse homem; mesmo que desejem as águias de Zeus ao trono do deus levar essa carniça, nem assim, temendo uma conspurcação, hei de permitir que se enterre esse morto" (idem, v.1.039-1.043).

Segue-se um tenso diálogo no qual Creonte continua se defendendo do que ele entende serem ofensas e, por isso, ofendendo Tirésias, até que pede que o adivinho fale o que guardava oculto, apesar de, juntamente, afirmar que por nada mudará de idéia. Tirésias, então, lhe avisa:

\footnotetext{
“Tu, por tua vez, sabe que não verás muito tempo o sol cumprir seu giro diurno antes de pagar por esse morto o preço de outro morto do teu próprio sangue, pois lançaste lá embaixo um ser de aqui de cima impiedosamente dando a um vivo um túmulo, enquanto reténs, negando-o aos deuses ínferos, insepulto e sem exéquias, um cadáver. (...) Pouco tempo falta, em tua própria casa hão de uivar de dor os homens e as mulheres. Contra ti, clamando, hão de erguer-se as cidades cujos mortos só cães e feras souberam enterrar, ou a ave que levou aos lares seu bocado vil de carniça insepulta." (SÓFOCLES, 1965, v.1.065-1.084)
}

Tirésias sai conduzido pelo menino e fica Creonte confabulando com o Coro. O Coro convence Creonte a voltar atrás, alegando que tudo que Tirésias disse sempre aconteceu, logo, também as desgraças previstas por Tirésias sobre a casa de Creonte e sobre Tebas iriam acontecer. É assim que Creonte segue o conselho do Coro e vai, pessoalmente, junto com escravos, enterrar o morto e livrar Antígona da prisão subterrânea.

Um mensageiro chega ao palácio e narra ao Coro o que se passou nesta tentativa de reconciliação de Creonte com os deuses. A esposa de Creonte, Eurídice, entra no palácio e ouve a narração do mensageiro, que conta que Creonte e os 
escravos enterraram Polinices conforme as honras gregas e se dirigiram ao antro de pedra onde estava Antígona. Mas quando ali chegaram, Creonte ouviu a voz de Hémon e, quando desceu até a caverna, viu Antígona estrangulada com seu próprio véu - suicidou-se - e seu noivo - Hémon - estava atirado sobre ela chorando, sozinho. Creonte chamou o filho, mas ele, cheio de ódio, cuspiulhe na cara e tentou matá-lo com sua espada; Creonte fogiu e, então, Hémon, desesperado, voltou todo seu furor contra si, matando-se.

Eurídice sai de cena após saber do que sucedera ao filho e à Antígona.

Creonte chega com o cadáver de Hémon nos braços e admite ser o culpado da morte do próprio filho em função da loucura das leis ditadas por si próprio.

Entra outro mensageiro anunciando a morte de Eurídice que, ao saber da morte do filho, suicidou-se e lançou sobre Creonte a dupla acusação de assassinato: dela própria e do filho.

Creonte lamenta-se muito e pede para que, depressa, o levem dali, para que ele nunca mais veja o nascer de um outro dia. O Coro diz-lhe que nem precisa pedir, pois nenhum mortal jamais conseguiu fugir à sorte traçada.

\section{A PALAVRA ORACULAR}

É preciso desde já avisar que este artigo não trata de tomar a palavra oracular no seu caráter de predição ao qual quase que inevitavelmente somos levados quando pensamos em oráculo; ou seja, não se trata, aqui, da representação comum do oráculo enquanto o que, interpretado, simplesmente prediz ou adivinha o futuro.

Da mesma forma, não é simplesmente porque é dito ou enunciado por Tirésias que tem o estatuto de palavra oracular, mas porque o que é dito por Tirésias tem uma forma específica de enunciação que se situa no limite da comunicação corrente.

A palavra oracular é, de acordo com Rosenfield, a forma mais pura da linguagem, enquanto que ela não comunica apenas conteúdos determinados, mas remete a um contexto mais abrangente, assegurando a coerência e a convergência dos conteúdos isolados. Esse contexto mais abrangente que os conteúdos isolados, mas que assegura a coerência e convergência dos mesmos diz respeito a uma outra dimensão da linguagem, dimensão esta que faz aparecer a representação ela mesma. É esta última que, nas palavras de Rosenfield, “assegura a convergência dos elementos particulares, e isto, apesar do fato de as contradições e ambigüidades subsistirem" (ROSENFIELD, 2000, p.293). Esta dimensão da linguagem para a qual aponta e na qual se move a palavra oracular apresenta-se, de saída, como diferente da linguagem do discurso racional e argumentativo, pois permite a subsistência de contradições e ambigüidades enquanto, como sabemos, o discurso racional não aceita. E é somente por permitir a subsistência 
de contradições e ambigüidades que ela consegue assegurar a convergência dos elementos particulares ou dos conteúdos isolados, pois eles muitas vezes são contraditórios entre si.

Assim, o que diz Tirésias - sua palavra - se articula de certo modo específico, de um modo diferente do modo como se articula o discurso argumentativo de Creonte e de Antígona. A palavra de Tirésias aponta para algo que está acima e, de certa forma, inclui os argumentos dos personagens referidos. A palavra oracular pode também ser chamada de palavra pura por fazer abstração de qualquer problema moral ou político e, justamente por tal abstração, consegue incluir tanto o argumento de Creonte quanto o de Antígona. Tais problemas - morais e políticos - seriam, então, a origem da oposição dos argumentos dos personagens da trama.

Mas palavra pura faz ainda outra coisa além da abstração de problemas morais e políticos envolvidos nos argumentos ou enunciados:

“' a palavra pura' (ou 'linguagem pura') da profecia constitui a palavra sui generis,
que não transmite apenas conteúdos determinados, mas, antes de tudo, uma espécie
de suspensão de todos os conteúdos - uma 'cesura' rítmica que permite ver, além das
relações incritas no ordenamento hierarquizado das representações sucessivas, outras
ordens possíveis entre os mesmos elementos.” (ROSENFIELD, 2000, p.294)

A palavra oracular, então, não apenas assegura a convergência dos elementos particulares ou dos conteúdos isolados, mas, o que é mais importante, suspende todos os conteúdos - ou seja, ela provoca um efeito de suspender os conteúdos dos argumentos de Antígona e Creonte - porque ela, com tal efeito de suspensão, aponta para esta cesura rítmica, ou seja, essa dimensão que une e liga sob outra lógica que a lógica apresentada pelos argumentos por meio dos seus conteúdos. É esta outra lógica para a qual a palavra pura aponta ou na qual ela se move que permite ver que os mesmos elementos ou conteúdos podem ser diferentemente ordenados.

Retomemos o texto trágico para explicitar de que modo a palavra ou discurso de Tirésias assegura a convergência dos elementos particulares e em que medida ela permite a subsistência das contradições dos discursos argumentativos de Creonte e Antígona e, mesmo assim, os inclui.

A contradição é clara quando se opõem os argumentos de Creonte e de Antígona: para Creonte, Polinices não pode ser enterrado porque é preciso fazer diferença entre ele que atacava Tebas para tomar o poder (o que, na lógica de Creonte o colocaria no lugar dos maus) e Etéocles que defendia a cidade (o justo na lógica de Creonte); enquanto que para Antígona Polinices deve ser enterrado por respeito às não escritas e intangíveis leis dos deuses subterrâneos. Dito ainda 
de outro modo, o embate em nível dos argumentos aparece, grosso modo, da seguinte forma: leis dos homens (do lado de Creonte) versus leis dos deuses (do lado de Antígona). Aparentemente, não há conciliação possível para os argumentos de Antígona e Creonte. No entanto, a palavra de Tirésias reordena os elementos ou conteúdos.

Tirésias se vale da arte dos áugures justamente enquanto visa apontar algo para além dos argumentos de Creonte e Antígona. Algo que está além e que inclui tais argumentos na medida que aponta para a necessidade de manter - enquanto ainda era possível, isto é, antes de Antígona suicidar-se - e, depois, de restabelecer o limite entre o mundo dos vivos e o mundo dos mortos. Com isso, o adivinho marca a necessidade de que se trate diferentemente tais mundos e seus representantes (deixando os vivos, vivos, e enterrando os mortos). Tal necessidade de limite representa (por isso no limite da comunicação corrente) a manutenção de todos os limites necessários à manutenção da vida, por isso não se trata (quanto à necessidade de enterrar Polinices) propriamente de fazer o bem ou a justiça (argumento de Creonte), nem de ser piedoso (argumento de Antígona). Dessa forma, tal conteúdo (o enterro de Polinices) aparece, a partir da palavra de Tirésias, sob outra lógica.

Entendo que, assim como faz a palavra oracular, a palavra do analista também visa provocar um efeito de suspensão do conteúdo dos enunciados contidos na fala de um analisante, na medida que aponta para a enunciação, ou seja, para esta outra dimensão - inconsciente - que funciona sob outra lógica que a lógica dos argumentos.

A lógica para a qual aponta ou a qual visa uma intervenção analítica é, de acordo com a teoria lacaniana, a lógica do significante.

O significante é apresentado por Lacan em "A instância da letra no inconsciente ou a razão desde Freud" (LACAN, 1957/1998) de forma semelhante ao que, antes, na aula do dia 10 de fevereiro de 1954 (LACAN,1953-1954/1986), Lacan havia definido como símbolo lingüístico. No texto dos Escritos, ele afirma que a estrutura do significante está em ele ser articulado de tal forma que suas unidades "estão submetidas à dupla condição de se reduzirem a elementos diferenciais últimos e de os comporem segundo as leis de uma ordem fechada" (LACAN, 1957/1998, p.504). Os elementos diferenciais últimos do significante são os fonemas; e as leis de uma ordem fechada são as leis da cadeia significante. É justamente por essas propriedades do significante - de se reduzirem a fonemas e de se comporem em cadeias - que é possível pensar em entrecruzamento lingüístico ou na propriedade de entrecruzamento lingüístico de todo símbolo lingüístico, propriedade esta que foi apresentada da seguinte forma na aula acima referida: 
“(...) esta Verschlungenheit, propriedade de entrecruzamento (...). Verschlungenheit designa o entrecruzamento lingüístico - todo o símbolo lingüístico facilmente isolado é não só solidário do conjunto, mas recorta-se e constitui-se graças a uma série de afluências, de sobredeterminações oposicionais que o situam simultaneamente em vários registros." (LACAN, 1953-1954/1986, p.79)

As afluências, as sobredeterminações oposicionais e a simultaneidade nos registros de todo símbolo lingüístico se devem a esta estrutura articulada do significante em fonemas e cadeia.

Na aula de Lacan do dia 20 de novembro de 1957, constatamos que as formações de sentido são geradas numa fala pelas combinações do significante. Por meio do elemento diferencial último do significante - o fonema - podemos apreender a linguagem no nível de um registro elementar; "duplamente definido - como cadeia diacrônica e, no interior dessa cadeia, como possibilidade permanente de substituição no sentido sincrônico” (LACAN, 1957-1958/1999, p.52). Está, assim, nesse nível fundamental elementar das funções significantes - metonímia (cadeia diacrônica) e metáfora (cadeia sincrônica) - a potência original presente em toda a formação de sentido; presente, portanto, pelo menos em potência, em toda fala no sentido estrito, isto é, no sentido psicanalítico.

Portanto, os fonemas, enquanto elementos diferenciais últimos do significante, possibilitam esta cesura rítmica que permite ver outras ordens possíveis entre os mesmos elementos, na medida que eles permitem que o significado recalcado consiga vir à tona ou aparecer em diferentes, mas em certo sentido repetidas, significações.

A cesura rítmica aqui apresentada como uma característica da palavra oracular diz respeito ao que vemos aparecer, numa psicanálise, na fala de um paciente quando, por um efeito rítmico na sua fala, ele acentua ou isola algum fonema em especial e, com isso, faz ressoar outros sentidos que aquele que intencionalmente (ou conscientemente) desejava comunicar.

Se considerarmos que esse contexto mais abrangente que assegura a coerência e convergência de conteúdos isolados é ao que a palavra oracular remete, no caso da palavra do analista, enquanto aponta as repetições que aparecem na cadeia significante, também remete a um conteúdo mais abrangente e, no caso, inconsciente.

É assim que a palavra do analista numa análise suspende o valor corrente ou empírico do que é falado pelo analisante, dessa forma fazendo aparecer o equilíbrio rítmico que as une - os significantes, através do seu elemento diferencial último: os fonemas. A palavra do analista, assim como a palavra oracular, visa fazer aparecer a cesura rítmica que une as enunciações apesar dos conflitos subjetivos, das oposições e das contradições. Contradições estas que Rosenfield 
classifica como aparentes, pois, como já vimos, remetem a algo que as inclui. E sabemos também, desde Freud, que não há contradição no inconsciente, que, no seu registro, idéias opostas coexistem.

Dessa forma, a palavra de Tirésias tem o estatuto de oracular ou é palavra pura quando aponta para Creonte, ainda na primeira parte de seu oráculo, que o mal da cidade vem do querer de Creonte. É importante sublinhar que Tirésias não entra no nível dos argumentos, isto é, em momento algum ele faz uma análise moral, legal, ou político-religiosa. Não. Tirésias aponta para a desmedida do querer de Creonte, desmedida esta que fez com que ele promulgasse um edito praticamente impossível de ser obedecido; isto porque Creonte agiu movido pelo querer ser rei, ou seja, pelo querer ser reconhecido, sobretudo, como um rei justo que respeita as leis e quer o bem de todos.

O estatuto da palavra pura, portanto, é dado por essa outra lógica que ultrapassa a linha dos argumentos e que reconhecemos, numa psicanálise, ser a lógica do inconsciente que, como sabemos, aparece no ato de fala.

É assim que nesse querer desmedido, ele, que estava justamente na posição de poder efetuar a sempre desejada - porque nunca satisfeita - purificação de Tebas, acaba, mais uma vez, por poluir seu chão. Creonte assim o faz porque não respeita os limites entre os vivos e os mortos, ou o limite entre os homens, os deuses subterrâneos e os deuses olímpicos, uma vez que nega sepultura a um morto, filho da cidade, e dá sepultura a uma pessoa viva. É por isso que Tirésias insiste na necessidade de enterrar Polinices (SÓFOCLES, 1965, v.1.0161.030) bem como de libertar Antígona de sua prisão subterrânea (idem, v.1.068-1.071).

O essencial das intervenções de Tirésias, nos diz Rosenfield,

"é o fato que elas suspendem a lógica argumentativa e conceitual dos protagonistas recorrendo a uma dimensão mais abrangente na qual os enunciados, os gestos e as ações dos protagonistas encontram-se igualizados, surgindo a sensação de que eles poderiam agenciar-se segundo uma outra relação do que aquela que aparecia nos diálogos anteriores”. (ROSENFIELD, 2000, p.297)

Entendo que um dos objetivos de uma intervenção analítica é o de apontar para esta não-necessidade da relação entre os fatos relatados pelo analisante na sua história; não-necessidade no que diz respeito ao determinismo, ou seja, de as coisas serem de determinada maneira porque necessariamente devem ser assim. O sentido de necessidade aqui utilizado é o sentido aristotélico de necessidade, a saber, de algo que é e não pode não ser. No caso do que conta um analisante, sabemos que as coisas são de determinada maneira porque há algo do desejo deste que fala que faz com as coisas assim sejam. Se há nisto alguma necessidade, 
esta é da ordem do desejo, ou seja, da ordem dos significantes e não da ordem do enunciado ou do discurso racional.

Lacan entende, seguindo a indicação de Freud da técnica da atenção flutuante ou equiflutuante, que um analista deve escutar igualmente a todos os significantes e não privilegiar alguns.

Dessa forma, uma vez que a palavra do analista recorre ou remete a uma dimensão mais abrangente da qual participam indistintamente todos os significantes, ela produz - ou visa produzir - no analisante a sensação de que outros agenciamentos seriam possíveis para o conteúdo por ele relatado, ou seja, visa produzir aberturas de sentido.

Como a palavra do adivinho recorre a uma dimensão mais abrangente que a dos enunciados dos argumentos dos protagonistas, tal palavra não deduz nem conclui a partir de um dos pressupostos da argumentação anterior, mas o adivinho

\footnotetext{
“dá a ver o ponto de fuga em que se insere os (significantes dos) interesses humanos num contexto maior, na totalidade cósmica (ou 'linguageira') - na 'potência da natureza selvagem', que é 'excêntrica' em relação aos interesses humanos e ameaça levar o homem em direção do abismo da 'potência natural' ou rumo ao 'tempo torrencial’”. (ROSENFIELD, 2000, p.299)
}

A palavra do analista, assim como a palavra oracular, deslinda a inevitável relação e referência ao Outro num ato de linguagem, ou seja, numa fala. Ela insere o sujeito, assim, nessa relação com o Outro enquanto tesouro dos significantes, logo, enquanto totalidade linguageira que antecede e ultrapassa o sujeito.

Apontando para a desmedida do edito proclamado por Creonte, Tirésias está apontando para o deinos que foi cantado pelo Coro no hino ao homem, isto é, ele aponta para este modo próprio do homem ser, ao mesmo tempo, maravilhoso e terrível, enquanto esta audácia ou esta dimensão formidável do homem nos seus esforços civilizatórios pode, como muito bem coloca Rosenfield, "tanto provocar resultados benéficos, como causar conseqüências catastróficas - embora nenhum escrutínio preliminar permita ao entendimento humano predizer a saída. Somente o tempo revelará progressivamente o valor da constelação arriscada" (ROSENFIELD, 2000, p.308). Como sabemos, é somente depois (après-coup)!

E no caso de Creonte, apesar de ter as melhores intenções e estar na posição de poder salvar Tebas do miasma, acaba não apenas não salvando a cidade, como introduzindo os miasmas ancestrais na própria família. Isto porque sua desmedida lhe impediu de ver o valor da palavra pura de Tirésias no momento em que se encontrava sob o fio da navalha. Era absolutamente necessário - enquanto que visava restabelecer os limites entre o humano, o sub-humano e o 
sobre-humano - que Creonte enterrasse Polinices, bem como liberasse Antígona de seu sepultamento viva. Mas ele não conseguiu reconhecer algo do seu desejo na lógica dos significantes trazida por Tirésias; ele apenas conseguiu tomar as palavras do adivinho como ofensa e ambição. Foi assim que, no fio da navalha, Creonte imolou-se.

Recebido em 11/9/2006. Aprovado em 13/11/2006.

\section{REFERÊNCIAS}

ARISTÓTELES. (1999) "Poética”, in Os pensadores, Aristóteles. São Paulo: Editora Nova Cultural Ltda.

ÉSQUILO. (1975) "Sete contra Tebas", in Teatro completo. Tradução de Virgílio Martinho. Lisboa: Editorial Estampa.

LACAN, J. (1998) "A instância da letra no inconsciente ou a razão desde Freud”, in Escritos. Rio de Janeiro: Jorge Zahar Editor.

(1953-1954/1986) O Seminário livro 1, Os escritos técnicos de Freud. Lisboa: Publicações Dom Quixote.

(1957-1958/1999) O Seminário livro 5, As formações do inconsciente.

Rio de Janeiro: Jorge Zahar Editor.

ROSENFIELD, K. H. (2000) Antígona - de Sófocles a Hölderlin: por uma filosofia trágica da literatura. Porto Alegre: L\&PM.

SÓFOCLES. (1965) A Antígone. Transcrição de Guilherme de Almeida.

Petrópolis: Vozes.

Heloisa Helena Marcon

heloisamarcon@yahoo.com.br 